\title{
FATUM Y REVELACIÓN EN LA ENEIDA: UNA APROXIMACIÓN A LA IMPORTANCIA DE LOS SUEÑOS DE ENEAS
}

Minor Herrera Valenciano

\section{(9) $\odot \Theta \Theta$}

Esta obra está bajo una licencia Creative Commons

Reconocimiento-No Comercial-Sin Obra Derivada 



\title{
FATUM Y REVELACIÓN EN LA ENEIDA: UNA APROXIMACIÓN A LA IMPORTANCIA DE LOS SUEÑOS DE ENEAS
}

\author{
FATUM ANDREVELATION IN THE AENEID: AN APPROACH TO \\ THE IMPORTANCE OF THE DREAMS OF AENEAS
}

Minor Herrera Valenciano

\begin{abstract}
RESUMEN $^{1}$
En este artículo se analiza cada uno de los cinco sueños que tuvo Eneas como momentos esenciales en los que el héroe accede a información imposible de obtener por otras maneras. Así las cosas, en los sueños de Eneas, se revelará su destino y servirá de guía y consuelo para el héroe quien, gracias a esto, reencauzará su misión fundacional.

Palabras clave: sueño, destino, revelación, misión, consuelo.
\end{abstract}

\begin{abstract}
This article discusses each one of the five dreams that Aeneas had as essential moments when the hero access information impossible to obtain by other means. So, in the dreams of Aeneas, his fate will be revealed and will guide and comfort the hero who, thanks to this, will rechanneled his founding mission.

Key words: dream, fate, revelation, mission, comfort.
\end{abstract}

\section{Introducción}

Los sueños cumplen una función esencial en la Eneida, ya que es por medio de estos que se le revelará a Eneas, en varias ocasiones, el destino que lo aguarda o la manera de librarse de los males que están a punto de sucederle. En dicho texto, lo sobrenatural del sueño se encuentra en función de una misión: que Eneas funde Roma. Esto permite la legitimación de dicha ciudad así como de su gobernante desde fuerzas superiores e inefables.

M.L. Minor Herrera Valenciano. Universidad de Costa Rica. Departamento de Filosofía, Artes y Letras. Sede de Occidente. Costa Rica.

Correo electrónico: minorj2007@hotmail.com

Recepción: 05- 05- 2015

Aceptación: 27- 07- 2015 
Así las cosas, los mensajes oníricos con destinatarios humanos corresponden a un tipo especialmente importante revelación, debido a que representan no sólo la relación hombre-divinidad, sino que muestran la complementariedad de una perspectiva de los hechos apocopada que limita la posibilidad de obtener conocimientos favorables para el futuro y el saber absoluto de todo lo que está por venir.

Incluso el mismo Cicerón en su texto De adivinatione menciona que:

\begin{abstract}
Vetus opinio est iam usque ab heroicis ducta temporibus, eaque et populi Romani et omnium gentium firmata consensu, versari quandam inter homines divinationem, quam Graeci $\mu \alpha v \tau \iota x \dot{\eta}$ appellant, id est praesensionem et scientiam rerum futurarum. Magnifica quaedam res et salutaris, si modo est ulla, quaque proxime ad deorum vim natura mortalis possit accedere. Itaque ut alia nos melius multa quam Graeci, sic huic praestantissimae rei nomen nostri a divis, Graeci, ut Plato interpretatur, a furore duxerunt.

Es una vieja creencia, sostenida ya desde los tiempos de los héroes y ratificada, además, por el asentimiento del pueblo romano y de todas las gentes, la de quehay entre los seres humanos una especie de poder adivinatorio al que los griegos llaman mantiké, esto es, la capacidad de intuir y de llegar a saber lo que va a pasar. Se trata de una capacidad extraordinaria y salvadora,caso de existir, en virtud de la cual la naturaleza mortal podría acercarse en muy gran medida a la condición de los dioses. Y, de la misma manera que, en otros muchos casos, nosotros hemos sabido derivar palabras mejor que los griegos, así nuestros antepasados derivaron de 'deidades' su denominación para esta capacidad tan notoria, mientras que los griegos, según interpreta Platón, lo hicieron de ‘delirio'.2 (Cicerón, 1999, p. 5)
\end{abstract}

Lo anterior lleva a pensar en la posibilidad de que, en el contexto de la Antigüedad clásica, las divinidades acogían el deseo de otorgar, a los humanos, la posibilidad de conocer su futuro, lo cual forma parte de la tradición de pueblos anteriores al romano (griegos y etruscos).

En la mayoría de los casos, los dioses hacen llegar sus mensajes de un modo incomprensible para los humanos y tiene razón de ser así, ya que estos no corresponden a una estructura lógica tradicional, sino a una que va más allá de toda comprensión humana, por tal razón, se vuelve estrictamente necesario recurrir a un intérprete, o alguien con la capacidad de traducir a lenguaje humano, los susurros de la divinidad, es decir, un oráculo; un hombre o una mujer escogidos por el dios, tal como lo apunta Cicerón:

Hic magna quaedam exoritur, neque ea naturalis, sed artificiosa somniorum [Antiphonis] interpretatio
eodemque modo et oraculorum et vaticinationum: sunt enim explanatores, ut grammatici poëtarum.
Nam ut aurum et argentum, aes, ferrum frustra natura divina genuisset, nisi eadem docuisset quem
ad modum ad eorum venas perveniretur, nec fruges terrae bacasve arborum cum utilitate ulla generi
bumano dedisset, nisi hearum cultus et conditiones tradidisset, materiave quicquam iuvaret, nisi
confectionis eius fabricam haberemus, sic cum omni utilitate quam di hominibus dederunt ars aliqua
coniuncta est per quam illa utilitas percipi possit. Item igitur somniis, vaticinationibus, oraclis, quod
erant multa obscura, multa ambigua, explanationes adhibitae sunt interpretum.

En este terreno destaca cierto arte de interpretar los sueños — así como los oráculos y los vaticiniosque tiene gran importancia y que no es de carácter natural, sino artificioso. Pues, al igual que la naturaleza divina habría creado en vano el oro y la plata, así como el cobre y el hierro, si ella misma no hubiera enseñado de qué modo se podía llegar hasta sus venas, ni le habría dado al género humano los productos de la tierra o los frutos de los árboles con aprovechamiento alguno, si no le hubiese transmitido cuál es su forma de cultivo y de preparación, ni nos sería de ayuda alguna la madera, si no dispusiéramos de una técnica para su elaboración, del mismo modo, a todo aprovechamiento que los dioses dieron a los hombres va unida alguna habilidad concreta, mediante la cual poder obtener ese aprovechamiento. Pues bien, las aclaraciones de los intérpretes se han aplicado de la misma manera a los sueños, a los vaticinios y a los oráculos, ya que muchos eran oscuros y otros muchos ambiguos. ${ }^{3}$

De la cita anterior, es posible determinar una estructura comunicacional, con la que es posible comprender, al menos, el funcionamiento básico del proceso comunicativo profético. 
Así las cosas, se tendrá un emisor, que generalmente se trata de alguna deidad, Manes, entre otros; un receptor, que será el hombre (entiéndase hombre y mujer), por medio de un canal metafísico (sueños, oráculos, eventos sobrenaturales), interpretados de tal manera que se les halle un sentido lógico o que se les pueda atribuir cierta referencialidad con elementos de la vida del individuo, hecho que favorecería la acción rápida o la pronta preparación para afrontar los hechos venideros. De no ser así, sencillamente no serviría de nada, sería, parafraseando a Cicerón, como un metal precioso cuando se encuentra enterrado y nadie tiene ni la menor idea de cómo extraerlo.

En la Eneida, los cinco sueños proféticos que tiene Eneas pueden comprenderse en su totalidad si se parte de que estos corresponden a una adivinación natural, la cual se desarrolla en el instante preciso en que el hombre cae en un sueño profundo, ya que el alma de este se suelta del cuerpo (su realidad física) y eso le permite contactar con la divinidad (Manetti, 2010). Incluso Cicerón opinó al respecto:

\begin{abstract}
Atque haec quidem vatium ratio est, nec dissimilis sane somniorum. Nam quae vigilantibus accidunt vatibus, eadem nobis dormientibus. Viget enim animus in somnis liber ab sensibus omnique impeditone curarum, iacente et mortuo paene corpore. Qui quia vixit ab omni aeternitate versatusque est cum innumerabilibus animis, omnia quae in natura rerum sunt videt, si modo temperatis escis modicisque potionibus ita est adfectus, ut sopito corpore ipse vigilet. Haec somniantis est divinatio.
\end{abstract}

Pues bien, éste es, desde luego, el fundamento que tienen los vates, no muy distinto del de los sueños, pues lo mismo que les pasa a los vates durante la vigilia nos pasa a nosotros cuando dormimos. Y es que el espíritu se halla provisto de vigor durante el sueño, libre de los sentidos y de todo impedimento que pueda surgir de las preocupaciones, cuando el cuerpo yace y se encuentra prácticamente muerto. Como nuestro espíritu está vivo desde el principio de los tiempos y ha habitado junto a innumerables espíritus, puede ver cuanto hay en el mundo de la naturaleza, si es que, mediante una alimentación sin exceso y un beber moderado, llega a disponerse de tal manera que éste se encuentra despierto, mientras que el cuerpo se halla adormilado. Tal es la forma de adivinación propia del que sueña. ${ }^{4}$ (Cicerón, 1999, p. 115)

Los episodios proféticos se estudiarán a partir de su significación comunicativa, pues, en los casos que se analizarán, siempre participa, como emisor, un dios, los Manes de algún antepasado o algún ser relacionado con la religión, además de un receptor que puede ser un simple mortal o una divinidad, quien hará lo posible por interpretar el mensaje con el afán de adelantarse a los acontecimientos futuros.

Así las cosas, en este artículo se analiza cada uno de los cinco sueños que tuvo Eneas como momentos esenciales en los que el héroe accede a información imposible de obtener por otras maneras, pues en los sueños de Eneas se revelará su destino y eso servirá de guía y consuelo para el héroe quien reencauzará su misión fundacional.

\title{
2. El sueño y el submundo: conocimiento en el Más allá
}

Desde el mundo griego de la Antigüedad, la muerte y el sueño poseían una enorme cercanía; no obstante, estaban divinizados como Thánatos, dios de la muerte, e Hipnos, dios del sueño, ambos hijos de Nix, la noche. Esta cercanía daría pie a que las civilizaciones posteriores a la griega antigua relacionaran el sueño profundo con la muerte o que, a través del sueño, se abriera una puerta donde muertos y vivos pudiesen estar en contacto.

En el mundo romano prevalecía la idea de que la muerte acarreaba consigo la corrupción del cuerpo, sin embargo, no así del alma que se encontraba contenida en él. Por tal razón, se pensaba que el alma, una vez que viajaba al Más allá, llevaba consigo algunas impresiones de lo que había hecho en vida, es decir, que el alma retenía conocimientos que se 
iban con ella, pero que podían ser accesibles y favorables a los vivos. Por otra parte, en el caso de que se hubiese producido una muerte violenta o anticipada, el alma retendría la conmoción del momento en que acaeció el fallecimiento.

En el texto de la Eneida, las almas del inframundo no solo mantienen la forma que poseyeron durante la vida, sino que mantienen el afecto o el odio por aquellos con quienes trataron. Es posible distinguir una gran variedad de espíritus inquietos, que no logran descansar y, por tal razón, con bastante recurrencia se aparecen en sueños o en manifestaciones fantasmagóricas, con el fin de horrorizar o de guiar.

Para algunos estudiosos como Cumont (1957), Blázquez (1993a; 1993b; 2008), Martínez-Pinna (1994) o J.M.C Toynbee (1996), tal relación entre los muertos y los vivos, a través de ofrendas llevadas a las tumbas, apariciones espectrales y oraculares, establece un tronco común entre las religiones griega, etrusca y romana. De esta manera, es posible observar en el poema épico de la Eneida, pasajes concretos donde se recurre al tratamiento de la muerte, los funerales y el Más allá tal como lo concebían aquellas civilizaciones.

Unido a lo anterior, en la Eneida, vivos y muertos no están muy alejados entre sí; por el contrario, entre ellos existe una fluida interacción por medio de sueños, en los cuales el espectro se manifiesta y sirve de consejero para el héroe; pero no solo lo aconseja, sino que le revela el destino o secretos que jugarán un papel fundamental en la obtención de los objetivos del héroe, tal es el caso de Héctor, hijo de Príamo, quien revelará a Eneas su destino.

Por tales razones nada se encuentra más cercano a la muerte que el sueño. En la Roma antigua y en otras civilizaciones se creía que el sueño permitía el acceso al mundo de los muertos, pues se consideraba como un estado de fallecimiento temporal. Durante el sueño, podían ocurrir interacciones entre los vivos y los muertos; el vivo extraía valiosa información de estos contactos que le serviría para librarse de males y salir airoso en sus empresas.

Al respecto Cicerón menciona en De senectute que:

\begin{abstract}
Atqui dormientium animi maxime declarant divinitatem suam; multa enim, cum remissi et liberi sunt, futura prospiciunt. Ex quo intellegitur quales futuri sint, cum se plane corporis vinculis relaxaverint. Qua re, si haec ita sunt, sic me colitote,' inquit, 'ut deum; sin una est interiturus animus cum corpore, vos tamen, deos verentes, qui hanc omnem pulchritudinem tuentur et regunt, memoriam nostri pie inviolateque servabitis.
\end{abstract}

\footnotetext{
Ciertamente conocéis que nada hay más semejante a la muerte que el sueño. Los espíritus de los que duermen expresan en grado sumo su divinidad. Por eso se comprende que prevean acontecimientos futuros, y cómo será su futuro una vez que se hayan liberado plenamente de las ataduras del cuerpo. Si las cosas son así, «alabadme como a un dios, pues si el alma ha de morir al mismo tiempo que el cuerpo, también vosotros, que veneráis a los dioses, que vigilan y gobiernan toda esta hermosura, debéis conservar nuestra memoria piadosa e inviolablemente. ${ }^{5}$ (Cicerón, 2001, p. 22)
}

Para los pitagóricos, los sueños son los hijos de la noche, pero también son considerados los mensajeros de la luz, ya que ellos poseen un notable valor en cuanto permiten conocer el futuro, un acontecimiento inminente o revelan secretos que cambian el destino de las situaciones.

Lo más probable es que Virgilio por su cercanía con la escuela pitagórica (hecho que ha sido ampliamente estudiado por H. Bauzá, V. Cristobal y E. Nieto) y los postulados sobre los sueños y la muerte que esta promovió, retoma la idea de que en el sueño es posible la revelación de acontecimientos futuros o inmediatos importantes; sin embargo, es consciente de que no todos los sueños poseen dicha condición oracular, por tal motivo manifiesta: 
Sunt geminae Somni portae, quarum altera fertur

cornea, qua ueris facilis datur exitus umbris,

altera candenti perfecta nitens elephanto,

sed falsa ad caelum mittunt insomnia Manes.

Dos son las puertas del Sueño, de las cuales una se dice

de cuerno, por donde fácil salida se da a las sombras verdaderas;

la otra resplandece del brillante marfil que la forma

pero envían los Manes al cielo los falsos ensueños. ${ }^{6}$ (Virgilio, 1990, p. 95)

Así las cosas, ¿qué significado tendrá el hecho de que en Eneas realice su ascenso a la superficie, salga por una puerta de marfil y no por la otra?

Henry (1990) indica que para comprender dicho pasaje es necesario vincular el hecho de que el héroe saliera por la puerta de marfil con el papel desempeñado por su padre Anquises en el inframundo. De este modo, mientras que por la puerta de cuerno únicamente salen las sombras, pues es una salida fácil, por la puerta de marfil ascienden los falsos sueños, enviados por los Manes, lo que quiere decir que son agentes de acción y dado que Anquises forma parte de este conjunto, únicamente tiene la posibilidad de abrir la puerta de marfil y con ello brindarle una salida segura a su hijo Eneas.

Ahora bien, es mejor centrarse en la importancia que posee este acontecimiento para que el relato prosiga. Una serie de estudiosos, como Gotoff (1985) y López (2007), mencionan que el descenso a los infiernos en asociación con el sueño deviene en la posibilidad nula de que el héroe conserve los conocimientos revelados en el mundo. Así pues, a pesar de que su padre le ha mostrado no sólo el porvenir de su casta sino la manera en que se movilizan las almas en el Más allá, el principal de los troyanos olvida todo lo que le ha enseñado, al menos eso parece, pues no se dice por ninguna parte de la Eneida que transmita ese conocimiento el resto de sus compañeros, es más, de lo visto y de lo hablado en el Más allá no se vuelve a mencionar palabra alguna en ninguno de los libros subsiguientes.

Ese cruce del umbral de la puerta de marfil es el instrumento que convertirá a Eneas en un héroe desmemoriado, pues olvida las penas que menoscaban su corazón y menguan sus fuerzas; no obstante, al conocer su futuro - aunque luego lo olvide - se motiva, lo cual permitirá que el héroe continúe con la misión impuesta por los dioses. Se comprende de este modo, que el contexto en el que el sueño se relaciona con la muerte es idóneo para la obtención de conocimiento de orden cósmico y principalmente histórico y que su estimación es propia de un estatus de sabiduría que se encuentra por encima del terrenal y humano.

Virgilio deja en claro la posibilidad de sueños en los cuales es revelada información importante para el héroe, en ese sentido los Manes, de los que se hace referencia en la cita, poseen características premonitorias y, desde luego, la capacidad de ver hacia el futuro los dota de una inestimable importancia, pues apropiarse de tal conocimiento permitiría adelantarse a los hechos; por ejemplo, a Eneas, con bastante recurrencia, se le presentan apariciones oníricas, las cuales van enderezando su camino heroico hasta que alcanza el objetivo escrito por el Hado.

\section{Los sueños de Eneas: revelación y conocimiento}

Lo que Eneas sueña siempre posee un evidente carácter premonitorio, porque cada una de sus visiones lo incitan a llevar a cabo acciones específicas para alcanzar la meta de fundar la ciudad que dará origen a Roma. A lo largo de la Eneida, el héroe experimentará cinco sueños: uno con Héctor, quien le pide que huya de Troya; otro con los Penates, esto ocurre 
mientras se encuentra en Creta, donde piensa que fundará la ciudad; uno más con Mercurio, durante su estancia en Cartago, lugar que visualiza como el fin de su recorrido, pero que dejará por mandato divino; en la cuarta oportunidad sueña con su padre Anquises, quien le indicará que siga el plan de Nautes y que viaje al Averno para indicarle su destino y el de su raza; y, finalmente, el viejo dios Tiberino, quien desea indicarle al héroe que su viaje ha llegado al final, se le muestra en su quinto sueño.

En cualquiera de los casos anteriores (los cuales se describirán detalladamente posteriormente), el sueño cumple una función de suma importancia, ya que conforman la guía del héroe, una especie de mapa onírico que va indicando a Eneas el camino correcto para cumplir con su destino, con el objetivo dispuesto por los dioses.

El primero de todos estos sueños es en el que Héctor, principal de los troyanos, se le aparece a Eneas en un sueño para advertirlo de la invasión de los dánaos ${ }^{7}$ a Troya y de la ciudad que está a punto de ser destruida; pero no solo eso, también pretende exhortarlo para que huya de Troya y funde una nueva ciudad, donde el legado dárdano ${ }^{8}$ permanezca por siempre.

El espectro que se le aparece a Eneas no muestra a un Héctor vigoroso ni triunfante; más bien, lo que muestra es la imagen desgarradora de un héroe que ha sido ultrajado, arrastrado por Aquiles en su carro; un héroe cubierto de suciedad, con el rostro ensangrentado, la barba de su rostro desarreglada y escuálida, y la espalda y piernas llenas de emponzoñadas heridas.

El pasaje es el siguiente:

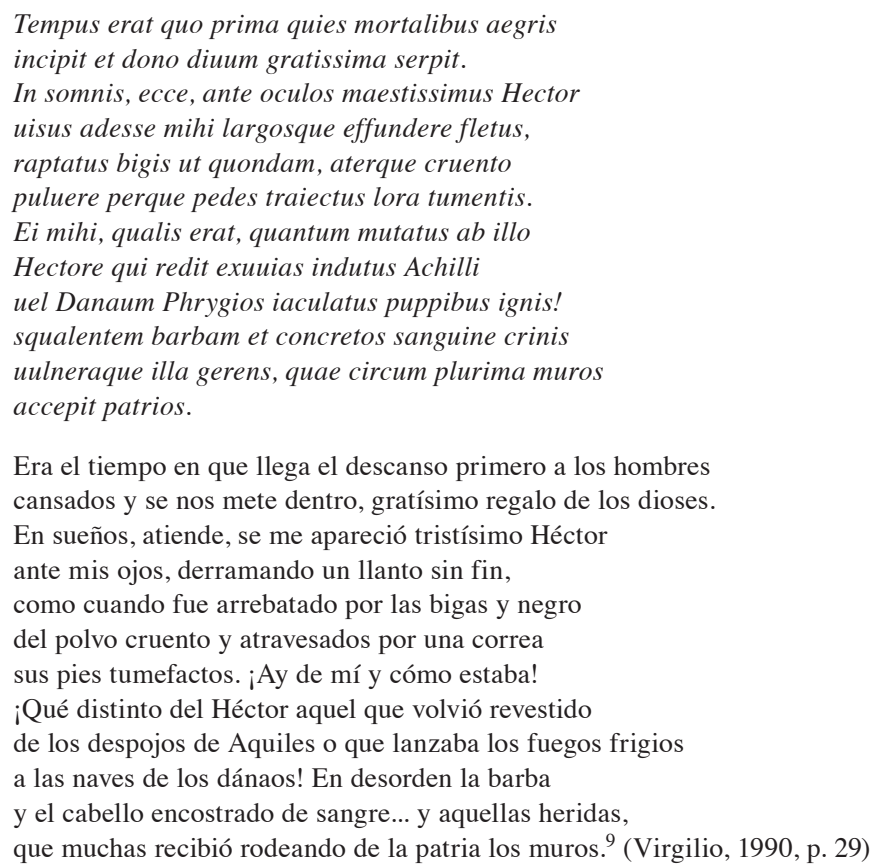

Como se nota, la manifestación fantasmagórica de Héctor en el sueño de Eneas, además de advertir del peligro, muestra la preocupación de un espíritu que no ha podido descansar en paz, debido a la pena que le causa el ver a Troya, su amada ciudad, reducirse poco a poco a cenizas. Se ha convertido en un alma que pena, pero no solo por haber perdido su vida, sino porque no desea ser observador del final de su pueblo. 
El alma en pena de Héctor entra en diálogo con Eneas como si estuviese con vida. Ese sueño premonitorio inicia el viaje que el héroe virgiliano emprenderá en busca de nuevas tierras, donde será posible levantar los muros de un nueva Troya.

La figura de Héctor, tal cual se presenta, proyecta la desgracia inexorable a la que Troya será sometida. Héctor, con el rostro cubierto de lágrimas, refleja el desconsuelo de un alma en pena y que no logró el paso al Más Allá adecuadamente, negro de sangre y polvo, pero le pedirá a Eneas que vaya en busca de sus compañeros, de su padre Anquises, de Creúsa su esposa y de su hijo Iulo, para que huya de Troya y lleve consigo los troia penatis, y otros objetos de valor o de orden sagrado, que deberán conservar y proteger bajo el abrigo de las nuevas murallas, que Eneas deberá edificar al término de su periplo.

Héctor se le presenta a Eneas lánguidamente, sin responder a las preguntas del héroe virgiliano y lo exhorta que salga de la llameante Troya:

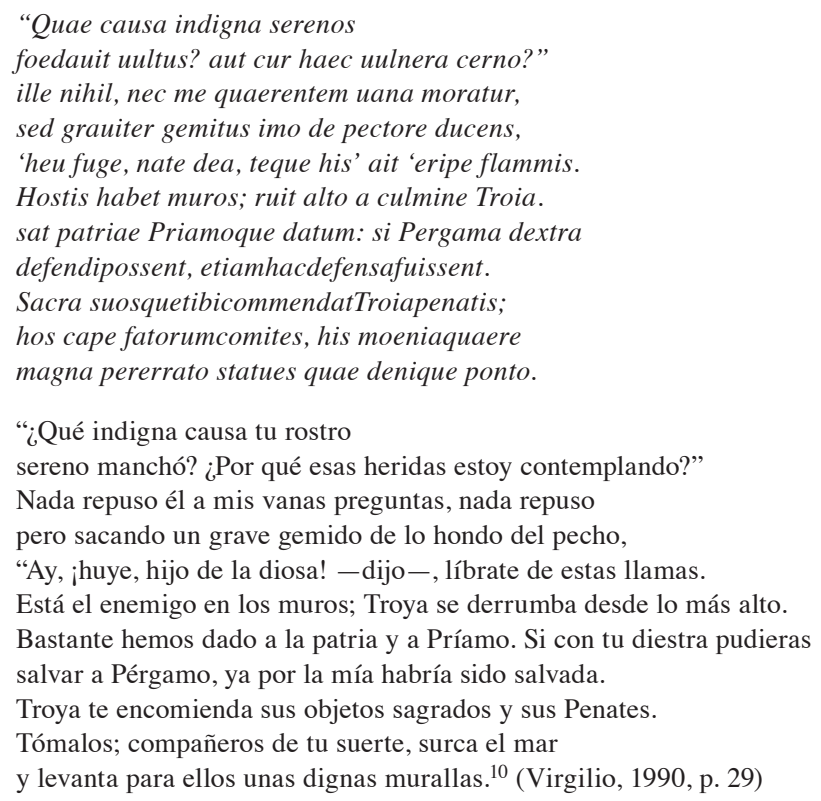

Los mortales (aún semidioses) no tienen la capacidad de advertir su futuro mientras están despiertos, como sólo pueden los vates. Es de esta forma que Eneas solamente puede acceder a tal conocimiento premonitorio por medio del sueño. El líder troyano, en el preciso instante en que es visitado por el espectro de Héctor, tal vez no se encuentra con plena seguridad de que aquello que presencia, forma parte de un sueño; no obstante, se percata de que aquella alma es la de su compatriota.

Eneas tiene pleno conocimiento del fallecimiento de Héctor y dado que ha transcurrido muy poco tiempo de tal acontecimiento se torna casi imposible que lo haya sacado su memoria. Es por tal razón, que no se asusta ante el espectro pues en este sueño no es considerado una pesadilla, antes bien, se percibe el asombro de Eneas al ver la figura demacrada del mejor guerrero de los troyanos y por esa razón procede a preguntarle qué lo ha llevado ahí, unido a otras preguntas acerca de la distribución del inframundo, cuál es su funcionamiento, qué pasa en el Más allá y, por supuesto, por qué aquella imagen fantasmagórica mantiene el cuerpo cubierto de heridas, pero ninguna de esas preguntas es contestada, antes bien, el fantasma toma 
la decisión de proporcionar una orden a Eneas: debe huir de Troya con los Penates. Por otra parte, le devela que será el fundador de una ciudad amurallada y edificada bajo el auspicio de los dioses troyanos, hecho que no sólo presenta la prolongación de la estirpe troyana, sino que certifica el papel de Eneas como líder de la empresa fundacional.

Ahora bien, cuál es la razón por la que las preguntas realizadas por Eneas no son contestadas por el fantasma de Héctor; una posibilidad sería que el fantasma no cuenta con mucho tiempo (por su condición de espectro o por tratarse de un sueño) y dada esa situación, unida a la urgente necesidad de comunicar lo verdaderamente útil para el héroe, no debe perderse tiempo en hablar acerca de cualquier otro asunto; la segunda posibilidad radica en que, dada su condición de humano "vivo", no es posible que Eneas acceda a un conocimiento únicamente alcanzable mediante la muerte. Únicamente por medio de su padre y con la valiosa colaboración de la sibila, quien lo conduce por los recovecos del inframundo, además, de la rama dorada con la que sobornan al barquero Carón, tendrá el troyano la posibilidad de atisbar cómo es el Más allá, a pesar de que dicho conocimiento por causa, desgraciadamente, de la salida por la puerta que Anquises señala, se pierda.

Por otra parte, es posible notar cómo ante la súplica que el espectro de Héctor le manifiesta a Eneas, este último no hace más que obedecer, ya que se da cuenta, tal vez por la desesperación con la que Héctor se dirige a él, de que la última esperanza del linaje troyano radica en su huida de Ilión y la posible fundación de una nueva ciudad donde las tradiciones permanezcan vivas por siempre.

Al respecto de este pasaje López señala lo siguiente:

\begin{abstract}
El sueño de Eneas es un pasaje de enorme tensión dramática; es la primera vez que el héroe hace mención de sí mismo y la hace en ellibro en que más está presente el destino que se manifiesta mediante sueños y apariciones. Es en este cuadro generaldonde se sitúa la aparición de Héctor a Eneas encabezando una serie de "autoridades" que le ordenan partir. De esta manera, el libro II no es sólo el libro de la caída de Troya, sino también ellibro de la huida, ordenada por dichas autoridades. Dicho de otro modo, la obediencia se impone como nuevo valor épico. La orden de partida y el abandono de la patria están justificados desde el punto de vista afectivo y desde el punto de vista divino. (1998, p. 365)
\end{abstract}

En relación con lo anterior, la falta de patriotismo de Eneas, como sería irse y no defender la ciudad hasta la muerte, queda absolutamente justificada en pro de una finalidad ennoblecedora y mucho más importante que alcanzar la gloria durante la batalla. Se ve liberado de un gran peso cívico, ya que por medio del nuevo mandato dado por Héctor, puede dejar de defender la ya de por sí acabada Ilión, para partir a fundar las bases de un nuevo comienzo troyano, que no solo se perpetuarán en Eneas y posteriormente en Iulo, sino que se fraguará y cimentará con la futura Roma.

Héctor insta a Eneas para que huya de Troya y le asigna una clara misión; sin embargo, la fatiga, las pérdidas de compañeros y otras vicisitudes hacen que Eneas desee establecerse en diversos lugares que no son los reservados para su estirpe. Por tal razón, los dioses Penates se le aparecen durante el sueño (segundo sueño), al igual que lo hace Mercurio, con el objetivo de hacerle ver al héroe que el sitio escogido es errado.

Así dicen los Penates:

Nox erat et terris animalia somnus habebat:

effigies sacrae diuum Phrygiique penates,

quos mecum a Troia mediisque ex ignibus urbis

extuleram, uisi ante oculos astare iacentis

in somnis multo manifesti lumine, qua se 


\begin{abstract}
plena per insertas fundebat luna fenestras;
tum sic adfari et curas his demeredictis: 'quod tibi delato Ortygiam dicturus Apollo est, hic canit et tua nos en ultro ad limina mittit. Nos te Dardania incensa tuaque arma secuti, nos tumidum sub te permensi classibus aequor, idem uenturos tollemus in astra nepotes imperiumque urbi dabimus. tu moenia magnis magna para longumque fugae ne linque laborem. Mutandae sedes. non haec tibi litora suasit Delius autCretaeiussitconsidere Apollo.
\end{abstract}

Era la noche y el sueño en la tierra se había adueñado de los animales.
Las sagradas imágenes de los dioses y los frigios Penates
que sacara conmigo de Troya en medio de incendio
de la ciudad se mostraron erguidos ante mis ojos,
en sueños, iluminados con gran resplandor, con el que la luna
llena se derramaba por las abiertas ventanas;
Y así hablaron entonces y con estas palabras se llevaron mis cuitas:
"Lo que Apolo te diría si volvieras a Ortigia,
aquí te lo revela y además nos envía a tus umbrales.
Nosotros te seguimos a ti, tras el incendio de Dardania, y a tus armas;
bajo tu guía hemos recorrido nosotros el mar hinchado con las naves,
seremos nosotros quienes alcen a los astros a tus descendientes
y confieran el imperio a tu ciudad. Tú dispón para grandes
grandes murallas y no abandones el enorme esfuerzo de tu periplo.
Debes cambiar de territorio. No de estas riberas te habló
el Delio, no te ordenó Apolo establecerte en Creta. ${ }^{11}$ (Virgilio, 1990, p. 41)

Los Penates mencionan que son enviados de Apolo, quien les ha pedido que deben aparecérsele durante el sueño a Eneas para indicarle el error que comete al pensar que ha llegado al final de su viaje. Eneas deberá obedecer y seguir adelante en la búsqueda de sus nativos umbrales.

Una situación similar ocurre en el tercer sueño, con la aparición del dios Mercurio en los sueños de Eneas, quien al igual que los Penates le recordará al héroe que su viaje está lejos de terminar y que el sitio que ha considerado para fundar una ciudad (Cartago) no es el que los dioses tienen pensado.

Eneas disfrutaba de un sueño profundo y reparador, cuando en medio de las imágenes oníricas se le apareció la viva imagen del dios Mercurio quien, en primera instancia, regañó a Eneas por estar dormido en un momento tan delicado y peligroso, posteriormente, le advirtió que aquella mujer, Dido, la reina cartaginesa, tramaba en lo más profundo de su pecho una serie de engaños y un horrendo crimen; además, le indica que dicha mujer está dispuesta a morir y su ira es tal que parece una tempestad.

Mercurio le pide a Eneas que despierte pronto y comparta con su gente las advertencias del dios, para que, cuanto antes, icen las velas de sus navíos y puedan escapar de la funesta ira de Dido. La huida debe ser inmediata, puesto que si se esperan verá "el litoral hervir en llamas, / si la Aurora te sorprende entretenido aún por estas tierras. / Ea, ánimo”. ${ }^{12}$

Ciertamente, Mercurio presiona al héroe y le advierte que se encuentra en un riesgo muy grande, el de permanecer en Cartago y olvidarse de fundar la ciudad que tiene por destino final. La intervención de Mercurio ${ }^{13}$ cambia la dirección de las acciones y hace que Eneas despierte del aletargamiento que lo mantenía en tierras cartaginesas. La mujer (Dido) es una tentación para el héroe, ${ }^{14}$ sumado a esto el deseo de descansar y establecerse; pero Mercurio 
es enfático al manifestar que no debe confiar su tranquilidad a la mujer, pues esta tiene las características de varium et mitable (inestable y voluble), es decir, que en un momento de volubilidad podría ser que Dido se tornase contra a él y su gente.

El pius Eneas accede a los mandatos divinos, como es propio de su condición, despierta a los remeros y sin que la reina cartaginesa se percate (hecho que traerá consecuencias nefastas para Dido), emprende nuevamente el viaje hacia la tierra que se les tiene reservada.

Eneas sabe que hay una tierra que se le ha prometido a su pueblo; sin embargo, no conoce con certeza el lugar exacto donde descansará al final de su travesía. Por tal razón, una vez más, por medio de la aparición espectral del sueño, se le indicará qué hacer, para enderezar nuevamente su rumbo. Esta vez se trata de su padre Anquises, quien se le manifestará a través del sueño (cuarto sueño) y le presentará el destino que lo aguarda. El pasaje completo es el siguiente:

Et Nox atra polum bigis subuecta tenebat.

Uisa dehinc caelo facies delapsa parentis

Anchisae subito talis effundere uoces:

'nate, mihi uita quondam, dum uita manebat, caremagis, natelliacisexercitefatis,

imperio Iouis huc uenio, qui classibus ignem

depulit, et caelo tandem miseratus ab alto est.

Consiliis pare quae nunc pulcherrima Nautes

dat senior; lectos iuuenes, fortissima corda,

defer in Italiam. Gens dura atque aspera cultu

debellanda tibi Latio est. Ditis tamen ante

infernas accede domos et Auerna per alta

congressus pete, nate, meos. Non me impia namque

Tartara habent, tristes umbrae, sed amoena piorum

concilia Elysiumque colo. Huc casta Sibylla

nigrarum multo pecudum te sanguine ducet.

Tum genus omne tuum et quae dentur moenia disces.

iamque uale; torquet medios Nox umida cursus

et me saeuusequisOriensadflauitanhelis.'

Dixeratettenuis fugit ceufumus in auras.

Y la negra Noche llevada por su biga ocupaba el cielo.

Caída entonces del cielo se le apareció la imagen de su padre

Anquises de pronto que le infundía estas palabras:

«Hijo a quien quise un día más que a mi vida, cuando la vida

tenía, hijo a quien han probado de Ilión los hados,

aquí llego por orden de Jove, que apartó el fuego

de tus naves y se compadeció al fin desde el alto cielo.

Atiende los consejos que ahora te brinda bellísimos

el anciano Nautes; llévate a Italia jóvenes escogidos,

los más esforzados corazones. Tendrás que pelear en el Lacio

con un pueblo duro y salvaje. Antes, sin embargo, entra

en las mansiones infernales de Dite y por el profundo Averno

ven, hijo, a mi encuentro. Que no me tiene el impío

Tártaro, las tristes sombras, sino que frecuento los amenos

concilios de los píos y el Elisio. Aquí la casta Sibila

te guiará con mucha sangre de negros animales.

Entonces toda tu raza conocerás y qué murallas te aguardan.

Y ahora, adiós; dobla la mitad de su carrera la húmeda Noche

y cruel Oriente me ha soplado el aliento de sus caballos.»

Había dicho y escapó a las auras tenue como humo. ${ }^{15}$ (Virgilio, 1990, p. 77) 
El espectro de Anquises se manifiesta para aclarar los pensamientos de Eneas, pero su función va más allá, pues lo que pretende es encaminar a su hijo hacia los campos Elíseos para mostrarle el destino de su raza. Es un acontecimiento motivador, pues hace ver a Eneas que su viaje tiene un verdadero sentido y que realmente existe una tierra que aguarda por él y su gente.

Al respecto Campbell (2008) afirma que es en esta prueba, en el reencuentro con el padre, en la que "se abre la posibilidad de que el héroe derive esperanza y seguridad" (p. 123) ante el acontecer aciago de los hechos que le ha correspondido vivir, es decir, que la aparición de Anquises le transmite el empuje necesario para continuar su viaje hasta el final.

Finalmente, el quinto sueño de Eneas es el que le asegura la conclusión de su periplo. En tal manifestación onírica, el viejo dios Tiberino le indica al héroe que puede dejar de buscar, pues ha llegado a la tierra que le fue prometida por el Hado y por los dioses, el lugar donde su estirpe florecerá nuevamente. El pasaje es el siguiente:

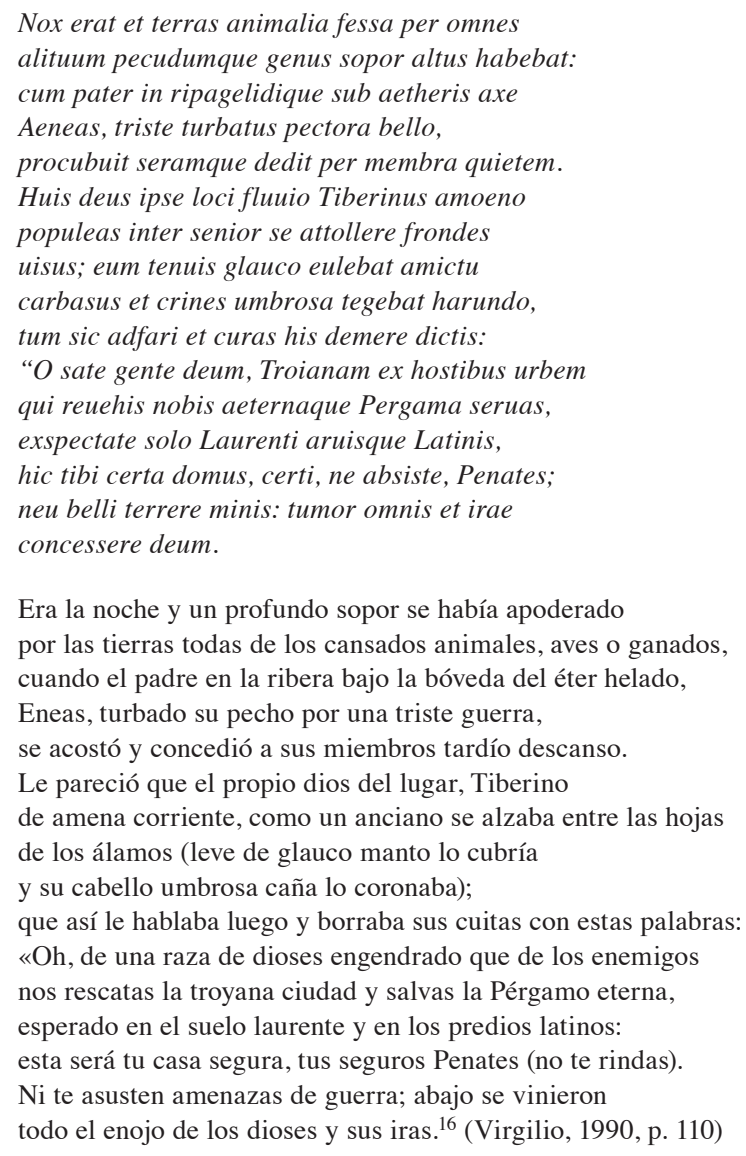

Es fundamental la importancia del sentido simbólico de este último sueño, pues es con un dios-río (el Tíber) estrechamente vinculado con la región y con la fundación de ciudades. Tal hecho remite al recuerdo de que las ciudades antiguas, por tradición y beneficio, se fundaban a orillas de un río, que conforma, desde la perspectiva de las estructuras de pensamiento mítico, el ordenamiento tierra-agua, el cual, a su vez abarca, la terna fecundidad-fertilidad-mujer. 
Finalmente, la intervención del dios acaba con la zozobra de Eneas, pues lo hace ver el final de su recorrido. Al fin Eneas podrá descansar del agotador viaje que ha emprendido en busca de sus nativos umbrales.

\section{Consideraciones finales}

Las revelaciones en los sueños poseen un rol preponderante en la Eneida, en tanto permiten una evolución en la psique de Eneas y una prosecución en la trama del texto. Por otra parte, conforman la manera en la que se estructura el "Hado" y su participación, además de referenciar el cosmos del que surgirá Roma. De esta manera, es mediante la participación de las divinidades o de los Manes de algún héroe glorioso y sus mensajes que se impulsará la edificación de una Caput mundi, que repose sobre las convicciones de grandeza sin límites, paz y gloria eterna.

En relación con lo que contiene cada una de las revelaciones, debe considerarse que se trata de una amalgama informativa en lo tocante al futuro troyano, aunado a un código de comportamiento que Eneas y los suyos deben asimilar y aplicar. Unido a lo anterior, cada sueño es parte del engranaje que representa la voluntad que las divinidades tienen con el líder de los troyanos (Eneas) y sus compañeros, ya que no se trata únicamente de conocer los tiempos venideros sino de estar al tanto de cómo funciona el mundo metafísico, etéreo, divino, cuestión que se torna imposible, pues, aunque los dioses mantengan algún grado de cercanía con los hombres, a través del sueño, la distancia entre los unos y los otros sigue siendo muy amplia.

Los cinco sueños se entrelazan entre sí de tal manera que es posible señalar un hilo conductor en cuanto al destino de Eneas, es decir, a partir de cada sueño, el héroe va descubriendo pistas que lo guiarán hacia su establecimiento final. Así las cosas, estos sueños se transforman en un mapa onírico con puntos de referencias y marcadores de posición que cambian la dirección de las acciones en el texto, ya que hay que recordar que Eneas se convierte en un huérfano, un héroe carente de arraigo, por lo que deberá buscar la tierra (y la mujer) que le proporcione los cimientos para establecer su pueblo y con quien establecer la unión simbólica. Además, su función es fundamental, ya que, desde la salida de Troya hasta la llegada a Lacio, en estos se le indica qué debe hacer y dónde debe llegar para cumplir su destino.

En todos los casos la sumisión con que obedece Eneas a los mandatos que recibe en los sueños singularizará al héroe virgiliano y lo convertirán en un modelo de aprobación, digno de ser imitado eternamente.

\section{Notas}

1. Tabla de abreviaturas:

\begin{tabular}{|l|l|}
\hline Cicerón & Cic. \\
\hline De adivinatione & Div. \\
\hline De senectute & Sen. \\
\hline Eneida & Aen. \\
\hline
\end{tabular}

2. Cic. Div. 1-5. La traducción que se sigue para esta cita como para el resto del artículo es la de Ángel Escobar (1999) de la editorial Gredos.

3. Cic. Div. 116-117.

4. Cic. Div. 1. 115 . 
5. Cic., Sen. 22. Fr. 81. La traducción que se sigue para esta cita así como para el resto del trabajo es la de Rosario Delicado Méndez.

6. Aen., 4. 893-896. La traducción que se sigue para esta cita así como para el resto del trabajo es la de Rafael Fontán Barreiro.

7. Este nombre lo reciben los argivos y también los griegos. Procede del príncipe egipcio Dánao, quien había buscado refugio en Grecia, donde erigió la ciudad de Argos.

8. Nombre que se le da a los troyanos. Dárdano fue quien fundó la estirpe troyana.

9. Aen., 2. 268-279.

10. Aen., 2. 285-295.

11. Aen., 3. 147-162.

12. Aen., 4. 554-579.

13. Hay que recordar que Mercurio tiene la habilidad de transportar almas al Más allá, por lo que está emparentado con la muerte y por lo tanto con el sueño.

14. Joseph Campbell (2008), en su texto El héroe de las mil caras, menciona que una de las etapas a las que todo héroe se enfrenta para alcanzar su plenitud heroica radica en lidiar con la mujer como tentación. En este apartado se menciona que el héroe se ve sometido ante los encantos divinales de una mujer o, en su defecto, de algún personaje que goce de principio femenino, hecho que lleva al personaje heroico a desviarse del camino que lo convertirá en un ser superior. Campbell cita a Shankaracharya, un monje hindú, para referirse acerca de la necesidad de alejar la tentación femenina: "Ya no puede el héroe descansar inocentemente con la diosa de la carne; porque ella se ha convertido en reina del pecado. En tanto que el hombre conserve algún afecto por este cuerpo que es como un cadáver, es impuro y sufre de sus enemigos, así como del nacimiento, la enfermedad y la muerte; pero cuando se piensa como ser puro, como la esencia de Dios y lo Inamovible, se vuelve libre... Alejad de vosotros esta limitación... No penséis más en ella” (2008, p. 115).

15. Aen., 5. 721-740.

16. Aen., 8. 26-41.

\section{Bibliografía}

Blázquez, J. M. (2008). Arte y religión en el Mediterraneo antiguo. Madrid. Cátedra.

Blázquez, J. M., Martínez-Pinna, J. et ál. (1993a). Historia de las religiones de la Europa Antigua. Madrid. Cátedra.

Blázquez, J. M., Martínez-Pinna, J. et ál. (1993b). Historia de las religiones antiguas: Oriente, Grecia y Roma. Madrid. Cátedra.

Cumont, F. (1957). After life in Roma Paganism. Lectures Delivered at Yale Univertity on the Silliman Foundation. New York: Yale University Press.

Cicerón, M. T. (1999). De adivinatione. (Á. Escobar, tr.). Madrid: Gredos.

Cicerón, M. T. (2001). De senectute. (R. Delicado-Martínez, tr.). Madrid: Cátedra.

Gotoff, C. (1985). The difficulty of the ascent from avernus. Chicago: University of Chicago Press.

Henry, E. (1990). The vigour of prophecy. A study of Virgil's Aeneid. Southen Illinois. Universy of Illinois Press.

López, S. (1998). Antecedentes y función literaria del sueño de Eneas y Andrómaca: Verg., Aen II 268-295 y Sen., Troad. 438-488. Revista EMÉRITA. 66 (2), 361-381.

López, V. (2007). Virgilio. Madrid: Letras Clásicas. 
Toynbee, J. M. C. (1996). Death and burial in the roman world. London: Thamer and Hudson. Virgilio. (1990). La Eneida. (R. Fontán-Barreiro, tr.). Madrid: Alianza. 